\title{
SWITCHING LOSSES CONSTRAINT IN MODEL PREDICTIVE DIRECT CURRENT CONTROL WITH $3 \varnothing$ VOLTAGE SOURCE INVERTER TO DRIVE
}

\begin{abstract}
${ }^{*}$ Anmar Kh. Ali ${ }^{1}$
1) Electrical Engineering Department University of Mustansiriyah, Baghdad, Iraq

2) Lecturer Electrical Engineering Department University of Mustansiriyah, Baghdad, Iraq
\end{abstract}

\begin{abstract}
The performance of $3 \varnothing$ VSI (voltage dc source inverter) is primarily based on its power losses occurring in semiconductor components. Complete losses in these components represent a total of losses in conduction and losses in switching. Many factors affecting the switching losses; system voltage, inverter output current, the system frequency, and the manufacturing specifications of the switching devices; with the use of a proposed constraint added to the objective-function in model predictive control strategy, these losses can be limited. This paper explores the reliance on the factors mentioned above for switching losses. A proposed algorithm based on adding a new constraint to the cost-function to reduce the switching losses and improve system efficiency. This was implemented using predictive direct current control for field-oriented induction motor drive. For the two cases of measuring the losses with and without the use of constraint were compared. A mathematical model is presented to measure the inverter switches. The measured power losses were compared before, and after applying for IGBT the proposed cost-function constraint taking into consideration the reduction in the THD.
\end{abstract}

Keywords: Predictive Current Control, Constraints, Switching Losses

\section{Introduction}

Power electronics devices are compelling and range from 97 to 99 percent of efficiency. Power losses in inverters occur primarily in semiconductor components (Insulated Gate Bipolar Transistor (IGBTs)), and their freewheeling diodes [1].

The overall losses in any switching device are the sum of power yields from the applied voltage and inverter current when the switch is conducting, and the losses produced when the device at the transition between ON and OFF states. For IGBT, the first type of power loss depends primarily on an $\mathrm{I}_{\mathrm{C}}$ and $\mathrm{V}_{\mathrm{CE}}$. The reduction of this type is hard to control since it depends on IGBT manufacturer parameters and junctions temperatures [1].

The switching losses occur at both the turn-on, and turn-off processes of the transistor operation and relies on: transistor applied voltage, the current passing through the transistor, the manufacturing specifications of the switch, and switching frequency; these factors rely on the junction temperature and the resistance in the gate-driver circuit in varying degrees. The losses from switching can be minimized by using constraints [1]. 
The goal of reduced losses, on the one hand, is to increase the performance of electric power inverters; on the other hand, fewer switching losses will contribute to an improvement of IGBT cooling conditions. Compliance with the additional need is often more important than efficiency improvement, particularly in medium and high-power inverters, this has a significant significance when inverters run with predictive current control applied to traditional fieldoriented control (FOC). Determining a transistor cooling method requires calculations including the switching losses, which in any transistor thermal model are one of the components of the heat source [1].

The cost-function represents the amount of deferences between the required reference value and its actual counterpart. This can be implemented for the most common converter variables. Mathematically Such an idea can be shown as [2]:

$g=\left|x^{*}-x^{p}\right|[1]$

where $\mathrm{x}_{(\mathrm{k})}{ }^{*}$ represents the required inconstant value and $\mathrm{x}_{(\mathrm{k})}^{\mathrm{p}}$ is its counterpart predicted one. This function is calculated for a given horizon. Usually, (1) can take many forms i- absolute, square, or integral errors Eqs. $(2,3,4)$ [2]:

$g=\left|x_{(k)}^{*}-x_{(k)}^{p}\right|[2]$

$g=\left(x_{(k)}{ }^{*}-x_{(k)}^{p}\right)^{2}[3]$

$g=\left|\int_{k}^{k+1}\left(x^{*}\left(t_{s}\right)-x^{p}\left(t_{s}\right)\right) d t_{s}\right|[4]$

The use of one from the above expressions depends on the required accuracy, the execution time, and the number of terms included in the cost-function [2].
Regardless of the equation simplicity, it can deal with many system variables. One example of direct current control for $3 \varnothing$ systems can be implemented with (5) represented with two-axis currents [2]:

$g=\left|i_{\alpha(k)}^{*}-i_{\alpha(k)}^{p}\right|+\left|i_{\beta(k)}^{*}-i_{\beta(k)}^{p}\right|[5]$

(5) can be used with the $3 \varnothing$ dc source inverter, the traditional active front-end rectifier, and many types of matrix converter [2].

Also, direct power management with this kind of cost-function can be done [2].

$g=\left|P(k)^{*}-P(k)^{p}\right|+\left|Q(k)^{*}-Q(k)^{P}\right|[6]$

Another case of these cost-function structures includes the following correlations with two factors of various extents. That is the situation with predictive torque and flux power, which considers the accompanying cost-function [2]:

$g=\left|T_{e(k)}^{*}-T_{e(k)}^{P}\right|+\left.\lambda_{\psi}|| \psi_{(k)}\right|^{*}-\left|\psi_{(k)}\right|^{P} \mid[7]$

Where $\lambda_{\psi}$ represents the weighting factor that manages the distinction in the greatness of the accompanying two terms of reference. This factor may likewise be acclimated to adjust the hugeness of each end [3].

\section{Dynamic Power Losses}

This type of losses in the IGBT consists of losses from switches and power losses from drivers. The switching power losses are the sum of the upper and lower IGBT loss when these transistors in ON / OFF state and the losses at the recovery region as shown in figure 1 [4-5]. 


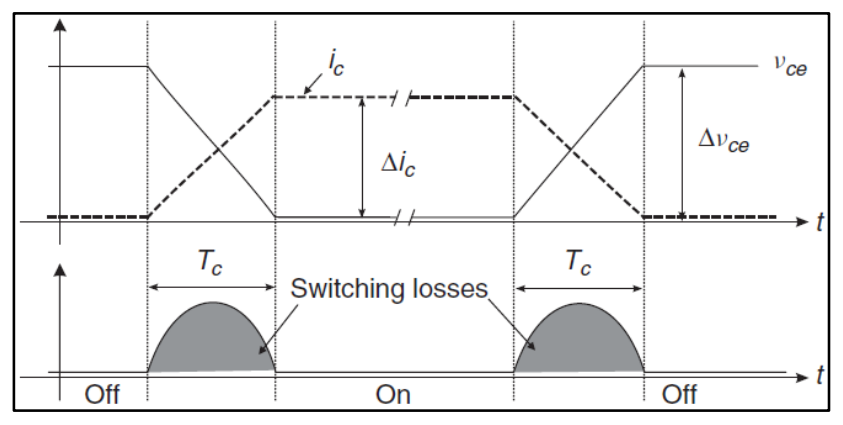

Figure 1: Basic model for estimating losses from switches

\subsection{ON/OFF State Losses Measurement for S1 IGBT}

A Matlab / Simulink simulation model is developed to compute the switching losses as shown in figures 4 and 5; a rise detector for gating signal S1 was developed to calculate the sum of the upper IGBT turn on/off cycles. To detect whether the upper IGBT in ON state or not is accomplished by recognizing the current polarity; the rising current gives a positive polarity and so on. Consequently, the model has to compute the numbers of this rising current occurrence which means the numbers of ON/OFF states for this transistor. The importance of the on / off losses in the datasheet of the vendor was associated with the average voltage and current. Eq. 8 demonstrates how to compute the upper IGBT ON/OFF state power losses [6].

$P=\frac{1}{T_{s}} \sum_{i=1}^{n}\left[i \times \frac{225 \times 10^{-3}}{750} \times \frac{E_{d c}}{600}\right][7]$

The same procedure is repeated for the lower IGBT.

\section{Actuation Constraints}

In converter control, any strategy has to consider the error minimization and the algorithm simplicity and its execution time, also the dependent of converter losses on the applied switching frequency. Using predictive control, to minimize it, any amount of control effort can be considered in the cost-function [8].

The predictive control strategy can be improved by adding more requirements as constraints to the main equation [8].

As with power converters, it is controlling the switching frequency represents the main goal for any control strategy. For many applications, it is necessary to control and monitor or limit the number of power switch commutations [9$11]$.

\section{Results and Discussion}

The Matlab/Simulink 2019 package is used in simulation. The system parameters are: $\mathrm{J}=3.1$ kg.m2, p = 2, Lm = 10.46 mH, Ls $=0.3027 \mathrm{mH}$, $\mathrm{Lr}=0.3027 \mathrm{mH}, \mathrm{Rs}=14.85 \mathrm{~m} \Omega, \mathrm{Rr}=9.295$ $\mathrm{m} \Omega$, Nominal Power $=149.2 \mathrm{kVA}$, Nominal Torque $=792 \mathrm{Nm}$, Nominal Flux $=0.73 \mathrm{wb}$, Nominal Frequency $=50 \mathrm{~Hz}, \mathrm{Ts}=2 \mu \mathrm{s}$.

The block diagram of the overall system is shown in figure 2.

To apply the proposed switching losses costfunction constraint, the algorithm must avoid two cases. The first one if there were more than two changes in the selected state of switches from $\mathrm{ON}$ state to OFF state and vice versa. This case can be avoided by supposing three voltage vectors that make the first scenario that has less than three switching changes. Then the algorithm decides and chooses the best voltage vector that gives the minimum cost- function by applying the predictive direct current control strategy, as shown in figure 3.

The second case if there was the seventh voltage vector with a sequence of (111) of upper switches. This case can be discarded by taking the previous sequence of switches that makes the change in the state of switches less than three changes. 


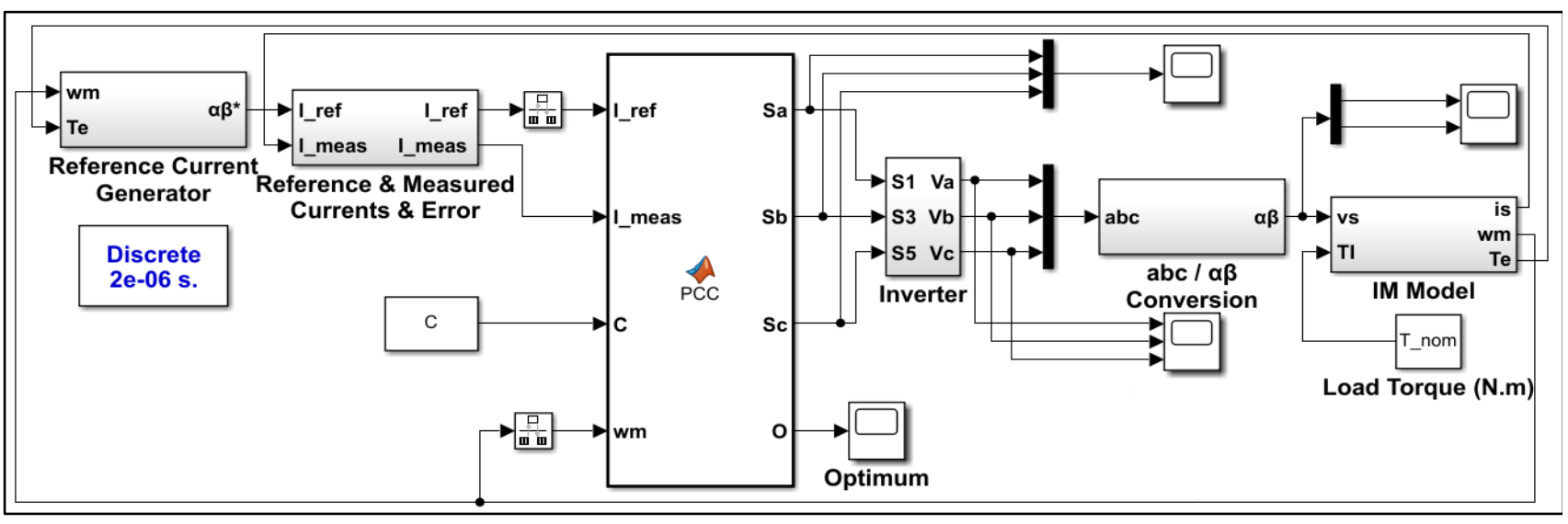

Figure 2: Block diagram of the overall system

To decide if the above-proposed constraint work or not, a simulation model is used to calculate the power loss in switches and compare it before and after applying constraint, this is shown in figures 4 and 5.

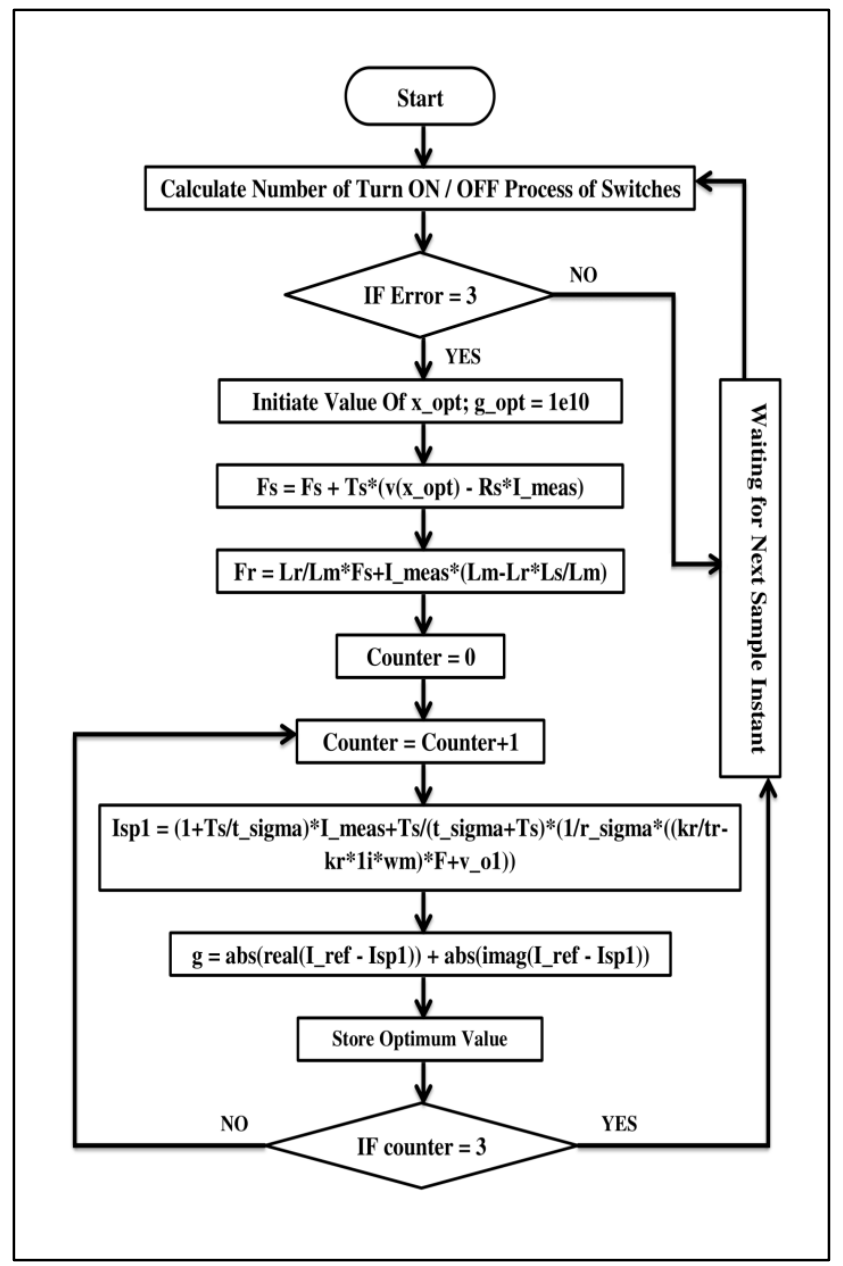

Figure 3: Flow chart of the switching losses constraint
This model consists of two blocks of gain. The first one calculates the absolute value of current and multiplies it by the number of power losses of turning ON/OFF. After that, the result will be divided by the accumulated value of the current. The second one having the number of power losses of turning ON/OFF from the first one and multiply it by $\mathrm{V}_{\mathrm{dc}}$ then the result divided by the main value of voltage.

This model detects the upper IGBT switching states then applying current, voltage, and the accumulated energy loss over the entire simulation time.

Figures 4 and 5 show a notable change in power loss, and this change will be more clear and effective in high power converters.

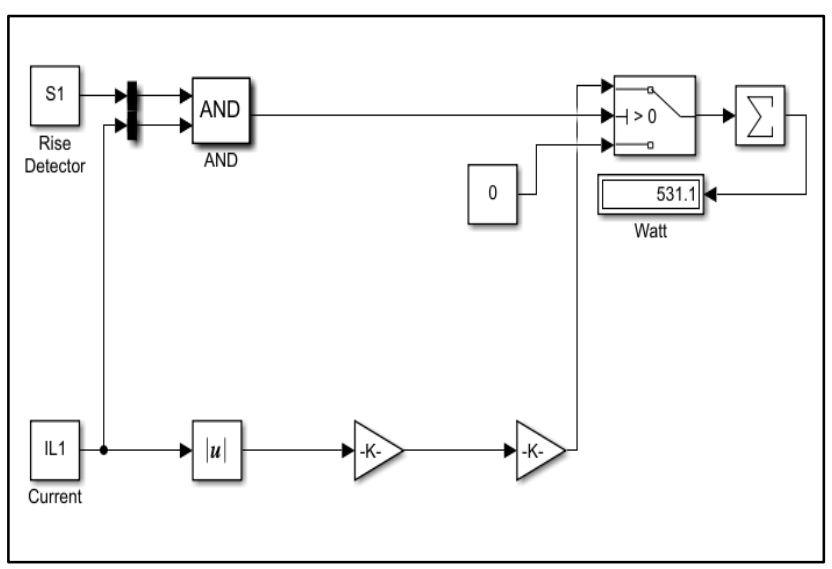

Figure 4: Power loss without Constraint 


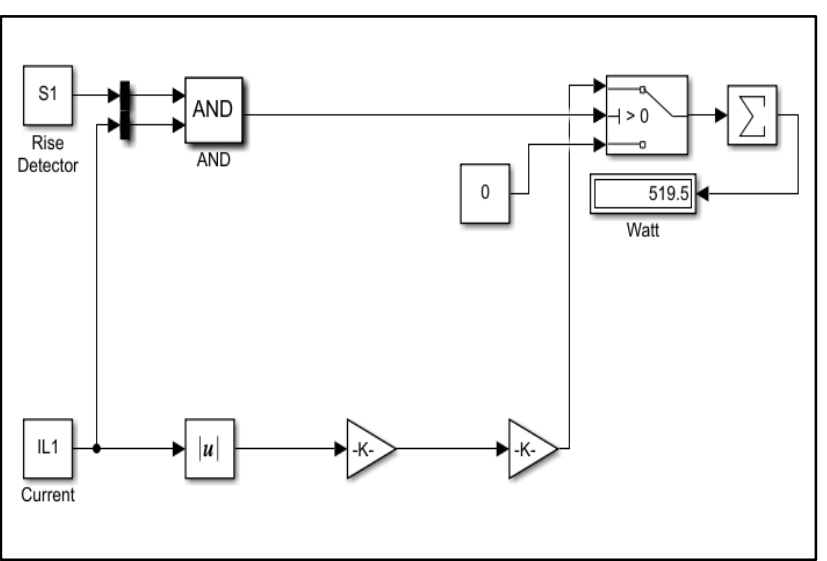

Figure 5: Power loss with Constraint

The currents of the calculated $3-\varnothing$ references are displayed in figure 6 .

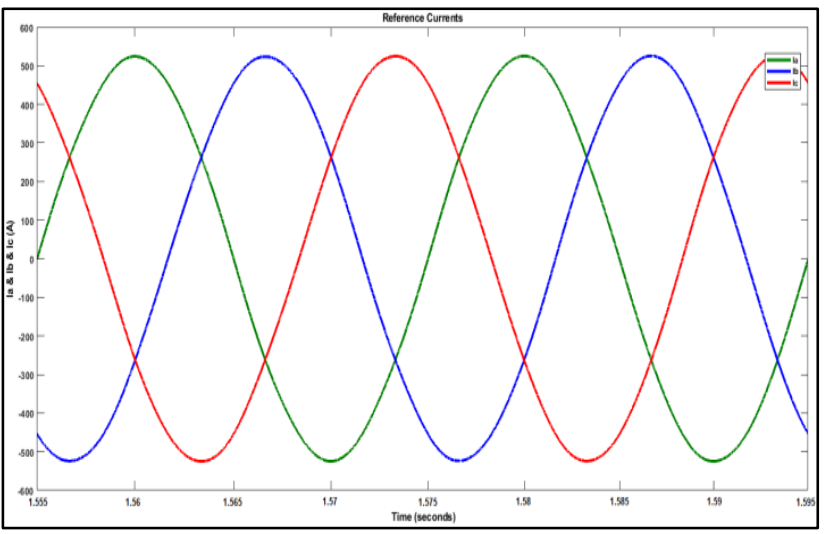

Figure 6: Generated reference $3-\varnothing$ currents.

Figures 7 and 8 , show that harmonics are increased when applying the constraint, but this can be tolerable for high power loss converters.

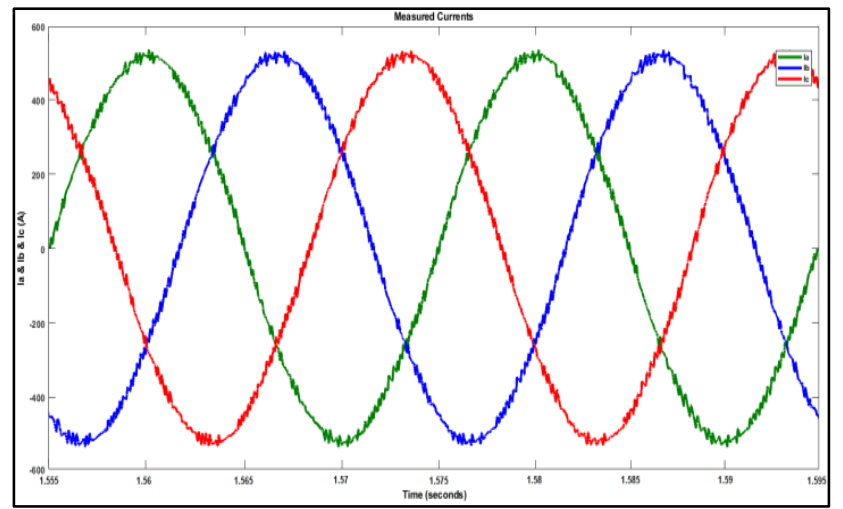

Figure 7: Measured 3- $\varnothing$ currents without constraint.

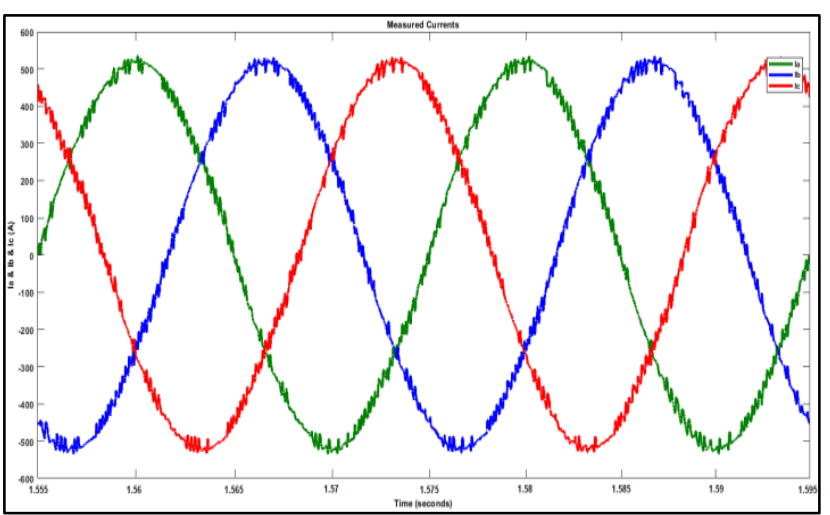

Figure 8: Measured 3- $\varnothing$ currents with constraint.

Figures 9 and 10, illustrate the increase in the harmonic content represented by THD when the proposed constraint is applied.

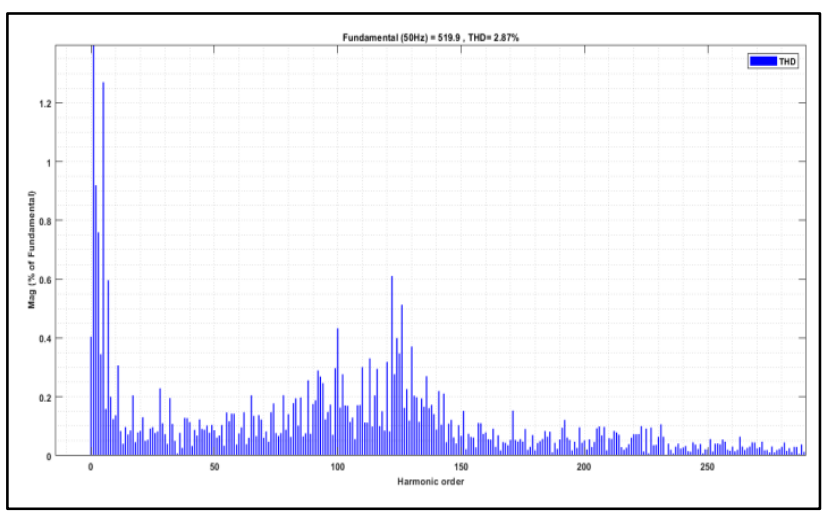

Figure 9: THD (2.87\%) without constraint.

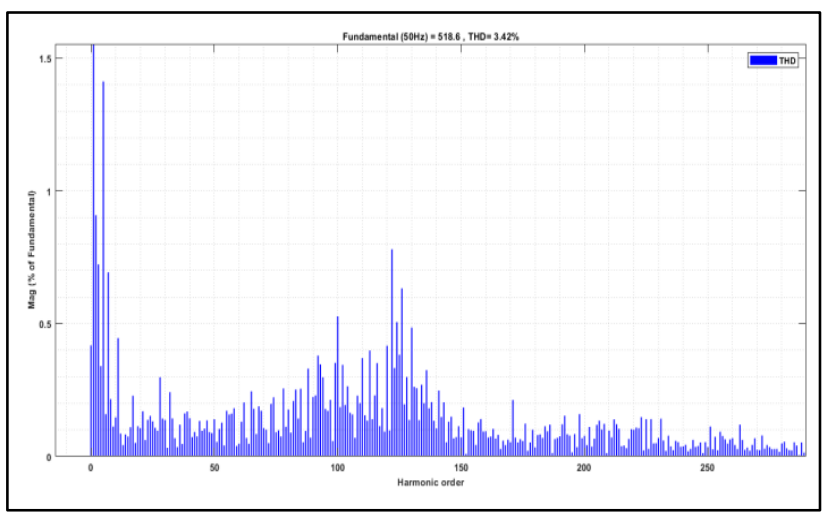

Figure 10: THD (3.02\%) with constraint.

Figures 11 and 12, showing how the optimum value of voltage vectors differs while using the constraint. 


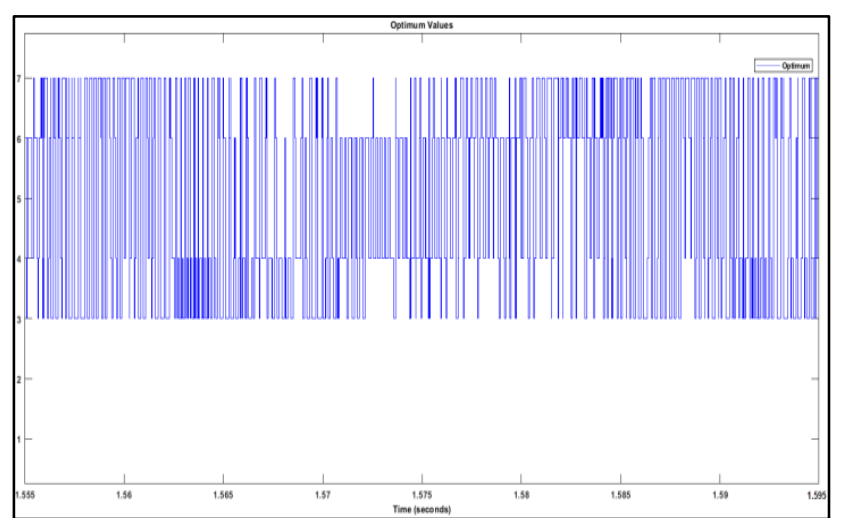

Figure 11: Optimum Value of Vector without constraint.

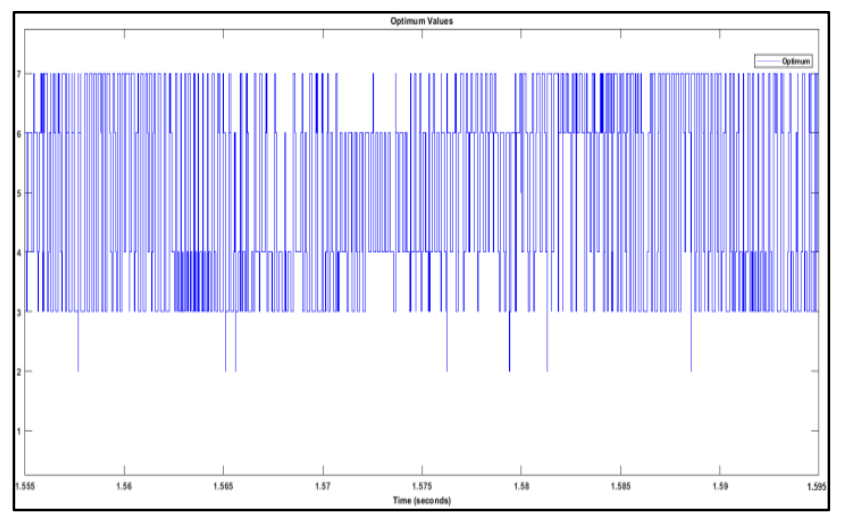

Figure 12: Optimum Value of Vector with constraint.

Figure 13 shows the reference speed, actual speed, and the difference between them.

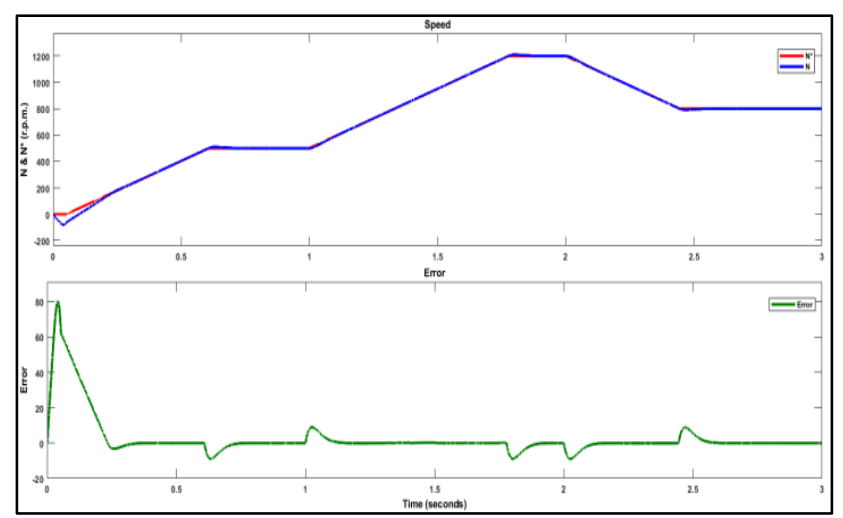

Figure 13: Reference, actual speed, and error.

Figure 14 shows the reference torque generating from the PI controller and electromagnetic torque.

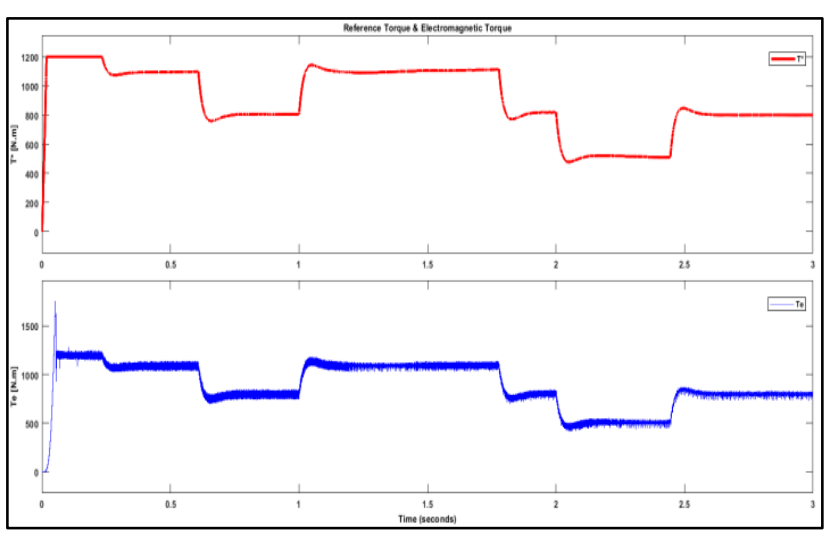

Figure 14: Reference torque and electromagnetic torque.

\section{Conclusions}

Switching losses in converter switches depend directly on the output voltage, load current, and increase with switching frequency (frequency of IGBT switches). Since recently, more converters work with the predictive direct current control approach, and a proposed constraint is added to the cost-function to reduce these switching losses by discarding any switching states that contain the highest losses. The results show a notable reduction in switch losses. The proposed algorithm has a drawback of increasing the output of current harmonic content slightly. Therefore, in high power converters, the proposed constraint of switching losses may be useful with applications that can tolerate more values of THD.

\section{Acknowledgments}

The authors wish to thank the academic advice and support from the Mustansiriyah University.

\section{Conflict of interest}

The publication of this article causes no conflict of interest. 


\section{Abbreviations}

MPC Model Predictive Control

FOC Field Oriented Control

THD Total Harmonic Distortion

IGBT Insulated Gate Bipolar Transistor

VSI Voltage Source Inverter

$3 \varnothing \quad$ Three Phases

PI Proportional Integral

\section{References}

1. J. Rodríguez, J. Pontt, C. Silva et al. (2007). Predictive current control of a voltage source inverter. IEEE Transactions on Industrial Electronics, Vol. 54, No. 1, pp. 495-503.

2. P. Cort'es, J. Rodr'iguez, P. Antoniewicz, M. Kazmierkowski (2008). Direct power control of an AFE using predictive control. IEEE Transactions on Power Electronics, Vol. 23, No. 5, pp. 2516-2523.

3. R. Vargas, J. Rodríguez, U. Ammann, P. W. Wheeler (2008). Predictive current control of an induction machine fed by a matrix converter with reactive power control. IEEE Transactions on Industrial Electronics, Vol. 55, No. 12, pp. 4362-4371.

4. R. Vargas, P. Cort'es, U. Ammann, J. Rodríguez, J. Pontt (2007). Predictive Control of a $3 \varnothing$ neutral point- clamped inverter. IEEE Transactions on Industrial Electronics, Vol. 54, No. 5, pp. 2697-2705.

5. F. Schafmeister, C. Rytz and J. Kolar (2005). "Analytical calculation of the conduction and switching losses of the conventional matrix converter and the (very) sparse matrix converter". In Conference Record of Applied Power Electronics Conference and Exposition, pp. 875-881.

6. R. Vargas, U. Ammann, J. Rodríguez (2009). Predictive approach to increase efficiency and reduce switching losses on matrix converters. IEEE Transactions on
Power Electronics, Vol. 24, No. 4, pp. 894902.

7. Ned Mohan, Tore M Undeland, William P Robbins (2003). "Power Electronics". $3^{\text {rd }}$ ed., John Wiley and Sons, Inc., Hoboken, New Jersey.

8. H. Miranda, P. Cort'es, J. I. Yuz, J. Rodríguez (2009). Predictive torque control of induction machines based on state-space models. IEEE Transactions on Industrial Electronics, Vol. 56, No. 6, pp. 1916-1924.

9. P. Cort'es, J. Rodríguez, D. E. Quevedo, C. Silva (2008). Predictive current control strategy with imposed load current spectrum. IEEE Transactions on Power Electronics, Vol. 23, No. 2, pp. 612-618.

10. S. Kouro, B. La Rocca and P. Cort'es et al. (2009). "Predictive control based selective harmonic elimination with low switching frequency for multilevel converters". In IEEE Energy Conversion Congress and Exposition, ECCE, pp. 3130-3136.

11. Isam M. Abdulbaqi, Ali Husain A., Riyadh G. Omar, Abdullah S. Abdulsada (2019). Modeling And Analysis Of A Four-Leg Inverter Using Space Vector Pulse Width Modulation Technique. Journal of Engineering and Sustainable Development. Vol. 23, No.02, pp. 100-119. 